\title{
Thymus Atrophy and Double-Positive Escape Are Common Features in Infectious Diseases
}

\author{
Juliana de Meis, ${ }^{1}$ Désio Aurélio Farias-de-Oliveira, ${ }^{1}$ Pedro H. Nunes Panzenhagen, ${ }^{1}$ \\ Naiara Maran, ${ }^{2}$ Déa Maria Serra Villa-Verde, ${ }^{1}$ Alexandre Morrot, ${ }^{1,2}$ and Wilson Savino ${ }^{1}$ \\ ${ }^{1}$ Laboratory on Thymus Research, Oswaldo Cruz Institute, Oswaldo Cruz Foundation, Avenue Brasil 4365, Manguinhos, \\ 21045-900 Rio de Janeiro, RJ, Brazil \\ ${ }^{2}$ Department of Immunology, Microbiology Institute, Federal University of Rio de Janeiro, 21941-590 Rio de Janeiro, RJ, Brazil
}

Correspondence should be addressed to Wilson Savino,w_savino@hotmail.com

Received 16 August 2011; Accepted 20 October 2011

Academic Editor: Mauricio M. Rodrigues

Copyright () 2012 Juliana de Meis et al. This is an open access article distributed under the Creative Commons Attribution License, which permits unrestricted use, distribution, and reproduction in any medium, provided the original work is properly cited.

\begin{abstract}
The thymus is a primary lymphoid organ in which bone marrow-derived T-cell precursors undergo differentiation, leading to migration of positively selected thymocytes to the T-cell-dependent areas of secondary lymphoid organs. This organ can undergo atrophy, caused by several endogenous and exogenous factors such as ageing, hormone fluctuations, and infectious agents. This paper will focus on emerging data on the thymic atrophy caused by infectious agents. We present data on the dynamics of thymus lymphocytes during acute Trypanosoma cruzi infection, showing that the resulting thymus atrophy comprises the abnormal release of thymic-derived T cells and may have an impact on host immune response.
\end{abstract}

\section{Introduction}

The thymus is a primary lymphoid organ in which bone marrow-derived T-cell precursors undergo differentiation, leading to migration of positively selected thymocytes to the T-cell-dependent areas of secondary lymphoid organs [2]. Interactions between thymocytes and specialized thymic microenvironmental cells (thymic epithelial cells, macrophages, dendritic cells, and fibroblasts) support and drive Tcell differentiation from bone marrow-derived precursors, by means of a series of interactions including receptor/coreceptor interactions, cytokines, chemokines, and hormones [37], as illustrated in Figure 1.

Thymopoiesis starts at the time that a T-cell precursor enters the thymus and interacts with local microenvironmental cells, which ultimately lead to their proliferation and further differentiation to the T-cell lineage. Various types of interactions take place, including those mediated by the class I and class II major histocompatibility complexes (MHC) expressed by microenvironmental cells, extracellular matrix proteins (ECM) such as laminin, fibronectin, and collagen, chemokines (as CCL25, CXCL12, CCL21), lectins such as galectin-3, various typical cytokines (IL-1, IL-2, IL-3,
IL-6, IL-7, IL-8, IFN-gamma, and others), sphingosin-1phosphate (S1P1), and hormones (thymulin, thymopoietin, thymosin-a1) [2, 5, 8-13]. T-cell differentiation depends on T-cell receptor (TCR) gene rearrangement and membrane interaction with MHC molecules.

The mechanisms by which progenitors home to the thymus have been suggested to be similar to those used by leukocytes to enter lymph nodes (selectins, chemokines receptors, and integrins) [1, 14, 15]. As soon as these thymic settling progenitors (TSP) enter the thymus close to the corticomedullary junction, they generate early $\mathrm{T}$-cell progenitors (ETP) or double-negative DN1 thymocytes, known to be $\mathrm{CD} 117 / \mathrm{c}-\mathrm{KIT}^{+}, \mathrm{CD} 44^{+} \mathrm{CD} 25^{-}$[16]. ETP or DN1 thymocytes evolve to DN2 and DN3 thymocytes that migrate to the subcapsular zone of the thymic lobules, where they rearrange the genes encoding the TCR beta chain, express pre-TCR receptor, and proliferate.

At the DN3 stage, the CXCL12/CXCR4 interaction contributes thymocyte proliferation and differentiation towards the DN4 and subsequently $\mathrm{CD} 4^{+} \mathrm{CD} 8^{+}(\mathrm{DP})$ stage $[1,17]$. Double-negative thymocytes, $\mathrm{TCR}^{-} \mathrm{CD} 4^{-} \mathrm{CD} 8^{-}$, represent $5 \%$ of total thymocytes. Maturation progresses with the definite acquisition of TCR, CD4, and CD8 expression 


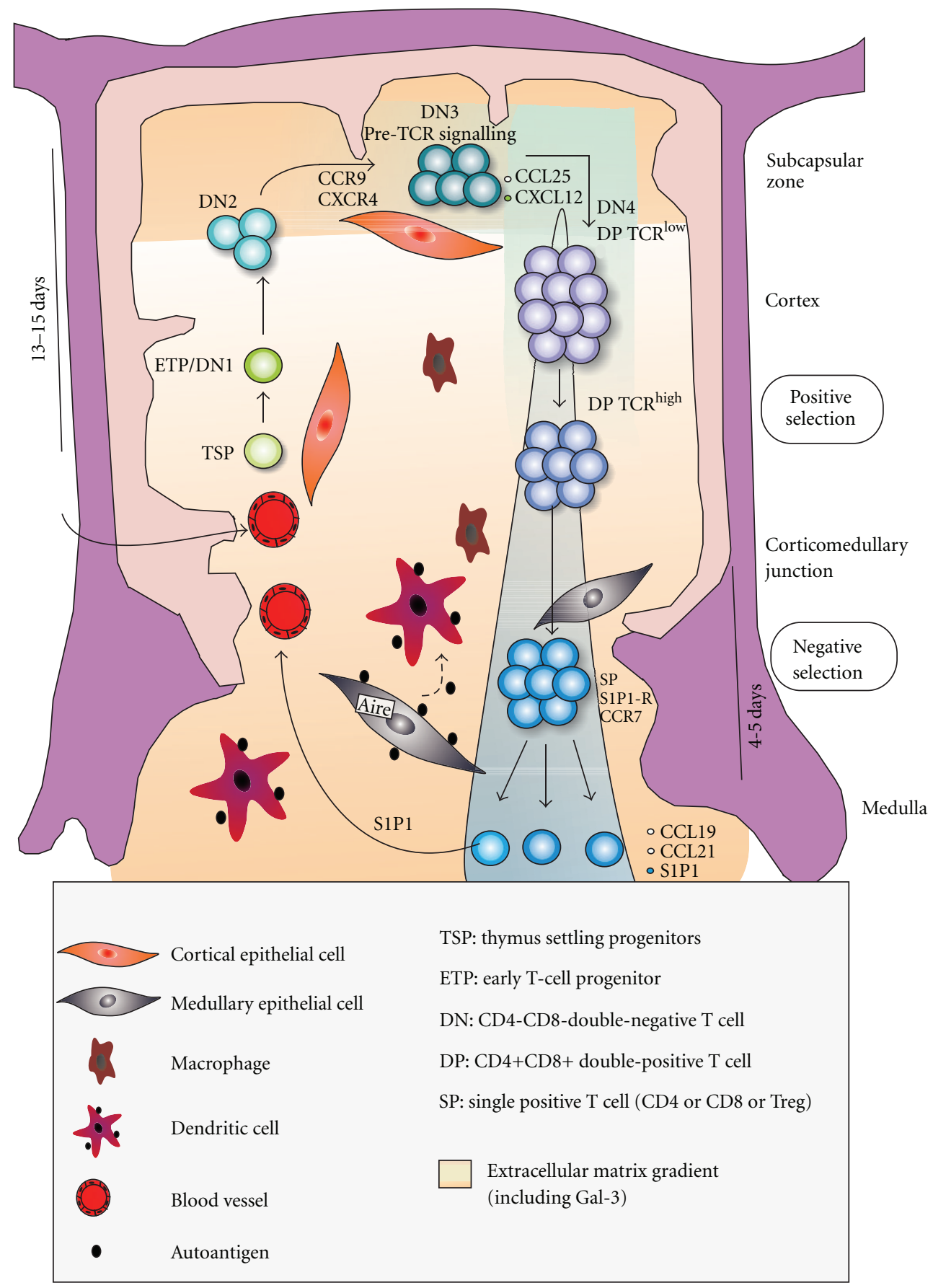

Figure 1: Intrathymic differentiation of $T$ cells. Lymphocyte differentiation initiates when T-cell precursors enter the thymus through postcapillary venules located at corticomedullary junction. After entering the organ, cells interact with the thymic microenvironment (thymic epithelial cells, macrophages, dendritic cells, and fibroblasts), which ultimately lead to their proliferation and TCR rearrangement. Interactions between thymocytes and specialized thymic microenvironmental cells support and direct $\mathrm{T}$ cell differentiation by means of a series of interactions including receptor/coreceptor interactions (MHC-TCR, Integrin/ECM Proteins), cytokines (IL-1, IL-2, IL-3, IL-6, IL-7, IL-8, IFN-gamma), chemokines (as CCL25, CXCL12, CCL21), and hormones, with corresponding receptors. At the subcapsular zone, these thymocytes undergo TCR beta chain rearrangement and selection. Double-positive thymocytes migrate through the cortex and initiate TCR testing (positive selection). Positively selected thymocytes, located at the medulla, are screened for self-reactivity through negative selection. Residence in the medulla is followed by emigration, which is regulated by sphingosine-1-phosphate and its receptor (S1P1). Adapted from [1]. 
generating DP; double cells, which constitute $75-80 \%$ of the whole thymocyte population. Thymocytes that do not undergo a productive TCR gene rearrangement die by apoptosis, whereas those expressing productive TCRs interact with peptides presented by molecules of the major histocompatibility complex (MHC), expressed on microenvironmental cells. The result of this interaction determines the fate of thymocytes $[2,9,18]$. The positively selected thymocytes will escape from apoptosis and become mature $\mathrm{CD}^{+}$or $\mathrm{CD}^{+}$single-positive (SP) T cells (Figure 1). This is a highly rigorous process, and only a small proportion of the doublepositive population survives [19]. Positive selection also results in lineage commitment so that the lymphocytes can be committed to either the CD4 or CD8 single-positive phenotype, depending on the class of MHC molecule with which the TCR interacts.

Intrathymic negative selection is essential to establish self-tolerance in the T-cell repertoire, deleting high-avidity TCR signaling thymocytes reacting to self-peptides presented by microenvironmental cells $[2,11,18,20]$.

Interestingly, along with $\mathrm{CD} 4{ }^{+} \mathrm{T}$-cell differentiation, two distinct groups of cells, with opposite roles, have been reported: the classical $\mathrm{CD}^{+} \mathrm{T}$ helper cells (cells that are able to trigger and/or enhance an immune response in the periphery) and regulatory $\mathrm{CD} 4^{+} \mathrm{CD} 25^{+} \mathrm{FOXP} 3^{+} \mathrm{T}$ cells, which are able to impair a given immune response $[9,21]$.

The data summarized above clearly demonstrate that the thymus is vital for the homeostatic maintenance of peripheral immune system, maturing both effector and regulatory T cells (Figure 1).

It has been well documented that the thymus undergoes an age-related atrophy [22]. Under normal circumstances, the decline in thymic cellularity in healthy subjects promotes minimal consequence. Nevertheless, over time, reduced efficacy of the immune system with age increases the rise of opportunistic infections, autoimmunity, and cancer [22-24].

In this paper, we present emerging data regarding accelerated thymus atrophy caused by infected agents and possible impact of this thymic atrophy to the host immune response. Moreover, we show that thymic-derived T cells are involved in the dynamics of lymphocyte populations in secondary lymphoid organs during acute Trypanosoma cruzi infection.

\section{Parasite Infection Promotes Thymic Atrophy with $\mathrm{CD4}^{+} \mathrm{CD8}^{+}$Thymocyte Depletion}

As mentioned above, the thymus senses several exogenous agents, responding with atrophy, promoted by viruses (HIV, rabies virus), parasites (Trypanosoma cruzi, Plasmodium berghei, Schistosoma mansoni, and Trichinella spiralis), and fungi (Paracoccidioides brasiliensis and Histoplasma capsulatum) $[9,22,25-40]$. The mechanisms involved in the thymic atrophy in infectious disease are not completely elucidated and may vary. Nevertheless, common histological features occur, including decrease of cortical thymocytes and loss of clear-cut distinction in the corticomedullary region $[9,38$, 41-47]. At least in some cases, such atrophy may be transient: biphasic reactions of the thymic cortex, characterized by initial atrophy and further restoration, were reported in

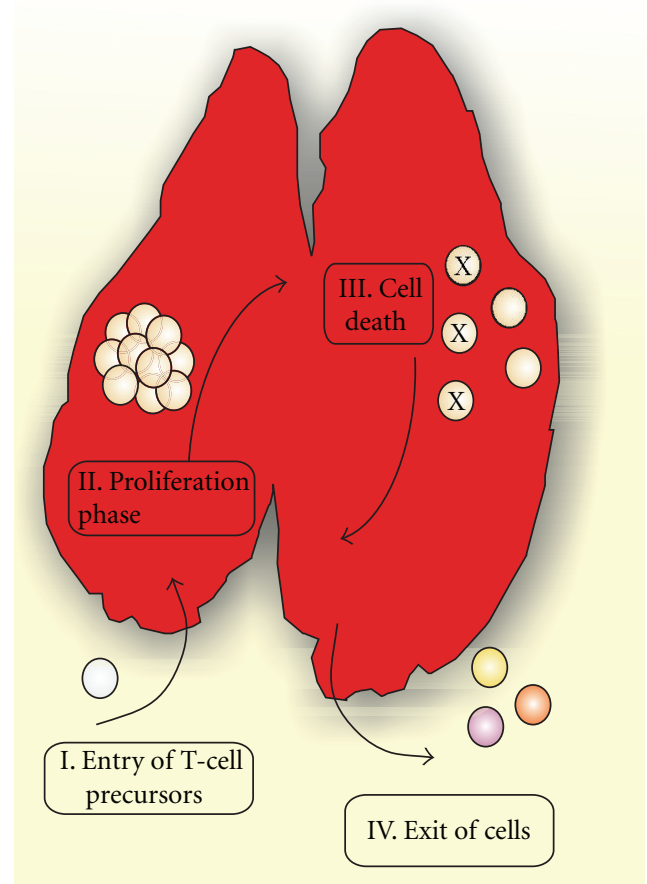

Figure 2: Possible mechanisms involved in thymic atrophy. I. Decreased number of precursor cells migrating into the thymus, II. Lower capacity in thymocyte proliferation during T-cell differentiation, III. Increased thymocyte death, and/or IV. Exit of immature T cells to peripheral tissues.

experimental infections by Histoplasma capsulatum and Toxoplasma gondii $[48,49]$.

Thymic atrophy in infectious disease may reflect distinct nonmutually excluding events: decreased number of precursor cell entry into the thymus, lower capacity in thymocyte proliferation, increased thymocyte death, and/or increased exit of thymocytes to peripheral lymphoid tissues (Figure 2).

Although the migratory capacity of T-cell precursors to colonize the thymus in infectious disease remains unknown, data from the literature suggest that parasite-induced thymus atrophy comprises changes in involvement of proliferation, death, and exit of thymocytes.

\section{Impaired Thymocyte Proliferation in T. cruzi-Infected Mice}

It has been shown that mitogenic responses of thymocytes from $T$. cruzi acutely infected mice are reduced due to decrease in interleukin (IL)-2 production, which in turn is associated with high levels of IL-10 and interferon- $\gamma$ [50]. It has also been suggested that changes in thymocyte subset proportions induced by $T$. spiralis infection are reflected in a reduced capacity of thymocytes to respond to the T-cell mitogen concanavalin A [45]. In contrast, thymocytes from S. mansoni-infected mice apparently exhibit similar concanavalin A-induced proliferative response, as compared to controls [38]. Conjointly, these data suggest that some (but not all) parasites induce decrease in the ability of thymocytes 
Box 1. Immunoneuroendocrine interactions involving cytokines and Hypothalamus-Pituitary-Axis in infectious diseases. Infectious agents lead to activation of innate and adaptive immune response. Proinflammatory cytokines (IL-1, IL-6, and TNF- $\alpha$ ) are key mediators of immune response and stimulate the Hypothalamus-Pituitary-Adrenal (HPA) axis. This HPA activation leads to increasing corticotrophinreleasing hormone $(\mathrm{CRH})$ by the hypothalamus and further production of Adrenocorticotropic hormone $(\mathrm{ACTH})$ by the pituitary gland. ACTH stimulation promotes adrenal production of steroids as glucocorticoids (GCs), dehydroepiandrosterone (DHEA), and its sulphate ester (DHE). GCs trigger apoptotic signals to $\mathrm{T}$ - and B-cell precursors as well as immature T cells [51-55]. In murine Chagas disease, there is an imbalance of the HPA axis, with increase in GCs levels, in the absence of rise in $\mathrm{CRH}$ and $\mathrm{ACTH}[56,57]$.

to proliferate, which in turn account for the resulting thymic atrophy.

\section{Thymocyte Apoptosis Is a Common Feature in Acute Parasite Infections}

In the vast majority of infectious diseases coursing with thymic atrophy, the major biological event associated with thymocyte loss is cell death by apoptosis, as seem, for example, in experimental models of Trypanosoma cruzi and Plasmodium berghei infection [9]. Although $\mathrm{CD} 4^{+} \mathrm{CD} 8^{+}$ thymocytes are the main target population in infection, other subsets as DN and SP cells also depleted in infected thymus $[30,32,42,63,64]$.

Glucocorticoid hormones are strong candidates to promote thymic atrophy and thymocyte death in parasitic infections. Serum glucocorticoid levels are upregulated in acute infections and promote DP thymocyte apoptosis through caspase- 8 and caspase- 9 activation $[9,56,57,65,66]$ (Box 1). Such rise in serum glucocorticoids has been reported in experimental parasitic diseases such as malaria, American tripanosomiases or Chagas disease, African trypanosomiases or sleeping sickness, toxoplasmosis, leishmaniasis, and schistosomiasis [51, 56, 67-72]. In experimental acute T. cruzi infection, thymic atrophy and thymocyte depletion have been associated with both TNF and glucocorticoid serum levels $[44,65,73]$.

Nevertheless, at least in T. cruzi infection, various and different biological mechanisms seem to be involved. T. cruziderived transsialidase, as well as host-derived galectin-3, extracellular ATP, and androgens have been pointed out as candidate molecules to enhance thymocyte death $[44,64,69$, 74-77]. Conversely, typical cytotoxic molecules such as Fas and perforin are not involved in thymus atrophy in T. cruzi infection [78].

\section{Acute Infection Can Promote Abnormal Escape of Immature Thymocytes to the Periphery}

T-lymphocyte migration is controlled by several molecular ligand/receptor interactions, including those involving ECM proteins, chemokines, and lectins [12, 13, 79-82].
In the thymus of mice acutely infected by $T$. cruzi or $P$. berghei alterations in expression of ECM proteins, chemokines, and/or galectin-3 have been described $[5,63,64$, $79,83]$, which is in keeping with the abnormal appearance of thymus-derived immature DP lymphocytes in peripheral lymphoid organs and blood from infected hosts. These findings suggest that the premature scape of immature cells from the organ also contributes to the establishment of the thymic atrophy $[38,42,84,85]$. Accordingly, it has been shown that thymocytes from $T$. cruzi acutely infected mice exhibited increased migratory responses to fibronectin and that abnormally high numbers of DP $\mathrm{T}$ cells migrate from the thymus to peripheral lymphoid organs. [42, 64, 83-86] (Box 2). Studies performed in experimental $P$. berghei infection have also demonstrated increased expression of ECM proteins, CXCL12 chemokine production, and enhanced migratory response of thymocytes from infected mice, when compared to controls [87].

\section{Thymic Changes May Impact on the Immune Response of Infected Animals}

Acute T. cruzi infection in mice leads to strong activation of innate and adaptive immune responses. Splenomegaly and expansion in subcutaneous lymph nodes (SCLN) were reported, mediated by persistent $\mathrm{T}$ - and $\mathrm{B}$-cell polyclonal activation [63, 88-91]. Conversely, atrophy in thymus and mesenteric lymph nodes (MLN) has been observed along with infection $[9,43,92]$. We have previously demonstrated that MLN atrophy in T. cruzi infection mice was associated with massive lymphocyte apoptosis, mediated by TNF, Fas, and caspase-9 $[63,88,92]$. The role of thymus-derived $\mathrm{T}$ cells in secondary lymphoid organ dynamics remains unclear. In order to analyze the role of the thymus upon regional immune response in secondary lymphoid organs from acute $T$. cruzi infected mice, thymectomized male $\mathrm{BALB} / \mathrm{c}$ mice or sham-operated counterparts were infected with 100 blood-derived trypomastigotes from Tulahuén strain of T. cruzi. In the peak of parasitemia (18-21 d.p.i), mice were killed, and subcutaneous, mesenteric lymph nodes as well as spleen were analyzed. As demonstrated in Figure 3, thymectomy in noninfected mice does not alter lymphocyte counts in the spleen, SCLN, and MLN. However, absence 
Box 2. Thymic atrophy and negative selection in experimental acute Chagas disease.

It is largely established that interactions between TEC and thymocytes control the development of the thymic microenvironment and T-cell development. Furthermore, many tissue-specific selfproteins are known to be synthesized by medullary thymic epithelial cells (mTEC) that express Aire. For this reason, Aire-expressing mTEC have a central role in the deletion of self-reactive thymocytes during the process of negative selection [58-61]. In T. cruzi infection we showed that the expression of Aire and highly selective tissue restricted antigens was readily detectable in whole thymus by real-time PCR analysis from infected mice, suggesting an expression of peripheral antigens which would be sufficient to modulate the tolerance induction by the negative selection process [62].

During the acute phase of infection, as the thymic atrophy becomes evident, there is an increase in numbers of apoptotic intrathymic DP cells, compared to their respective normal counterparts. Although this phenomenon may be a consequence of the changes observed in the organ, our data show that along the DP depletion there is sustained expression of Bim, a proapoptotic factor essential for thymocyte negative selection. Further analysis, by using an OTII TCR transgenic system, revealed that the administration of the cognate OVA peptide in the acutely infected mice undergoing thymic atrophy can induce TCR-stimulation-induced apoptosis of semimature thymocytes. These data point out that negative selection operates normally during infectionpromoted thymic atrophy, since the DP cells can be negatively selected in the infected thymus by antigen-induced depletion [62].

Box 2

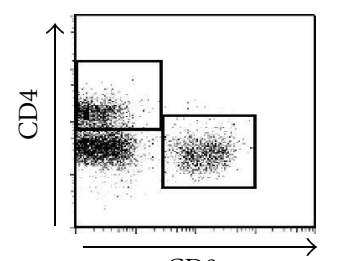

CD8
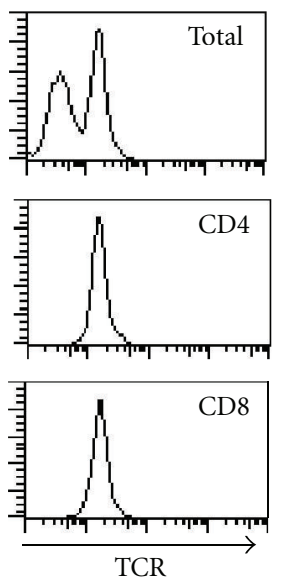

(a)

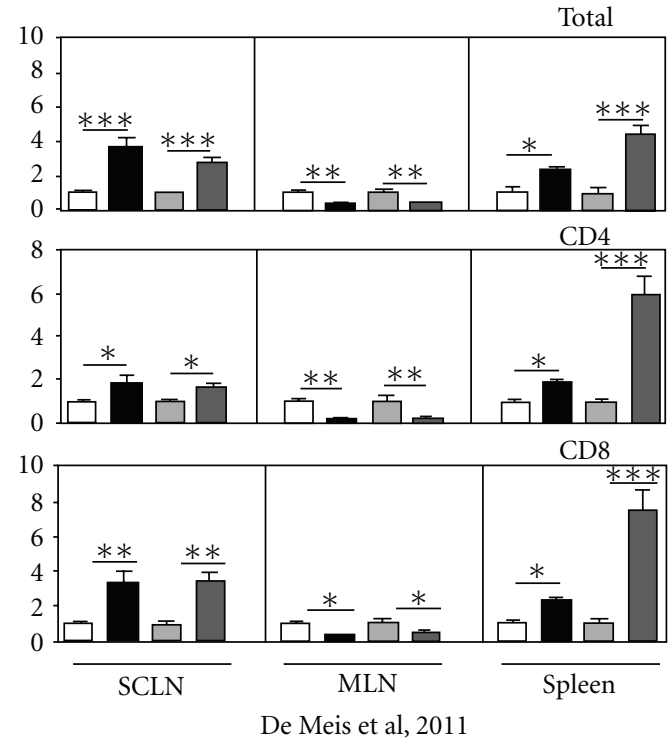

(b)

Figure 3: Thymectomy modulates splenic cell numbers during acute Trypanosoma cruzi infection. Mice were thymectomized and, six days later, were infected intraperitoneally by the Tulahuén strain of T. cruzi. Animals were killed at 19 days postinfection, and subcutaneous (SCLN), mesenteric (MLN), lymph nodes and spleen cell numbers were evaluated. (a) Representative data demonstrating TCR expression in CD4 and CD8 T cells in SCLN, MLN, and spleen, analyzed by flow cytometry. (b) Data show fold change of 6-8 animals/group where (white rectangle) represents sham-operated control, (black rectangle) sham-operated infected, (light grey rectangle) thymectomized control, and (dark grey rectangle) thymectomized infected mice. Results were representative of three different experiments and were expressed as mean \pm standard deviation, ns: not significant, ${ }^{*} P<0.05$, ${ }^{* *} P<0.01$, and ${ }^{* * *} P<0.001$, after comparison by One Way ANOVA.

of thymic-derived $\mathrm{T}$ cells during acute infection increased the number of splenocytes (Figure 3). In this respect, it has been demonstrated that thymus-derived $\gamma \delta \mathrm{TCR}^{+} \mathrm{T}$ cells removed from the spleen exhibit suppressor activity for T lymphocytes [93]. Moreover, as showed in thymectomized T. cruzi chronically infected animals, thymic removal may act by downregulating immunoregulatory mechanisms, leading to an exacerbation of autoimmune reactions believed to be involved in the generation of myocardial damage [94].

Interestingly, no changes were observed in SCLN cell expansion and MLN atrophy between infected sham and thymectomized mice, suggesting that suppressor $\mathrm{T}$ cells migrate 
preferentially to the spleen (Figure 3). All together, these data indicates that thymic-derived $\mathrm{T}$ cells can exert immunoregulatory in the spleen during acute T. cruzi infection.

\section{Conclusion}

Several pathogens, including T. cruzi, cause thymic atrophy. Although the precise mechanisms underlying this phenomenon are not completely elucidated, most likely it is linked to a particular pathogen-host relationship. Recently, we addressed whether the changes of the thymic microenvironment promoted by an infectious pathogen would also lead to an altered intrathymic negative selection of the T-cell repertoire. By using a T. cruzi acute infection model, we have seen that, despite the alterations observed in the cortex and medullary compartments undergoing a severe atrophy during the acute phase, the changes promoted by the infection in the thymic architecture do not affect the negative selection.

Although the intrathymic checkpoints necessary to avoid the maturation of $\mathrm{T}$ cells expressing potentially autoreactive "forbidden" T-cell receptors are present in the acute phase of murine Chagas disease, circulating $\mathrm{CD} 4^{+} \mathrm{CD} 8^{+} \mathrm{T}$ cells have been reported in humans as well as in animals such as mice, chicken, swine, and monkeys $[9,62,85]$. The existence of this unconventional and rare lymphocyte population in the periphery was explained as a premature release of DP cells from the thymus into the periphery, where their maturation into functionally competent single-positive cells continues.

Most importantly, there is considerable evidence of an increased frequency of peripheral $\mathrm{CD} 4^{+} \mathrm{CD} 8^{+} \mathrm{T}$ cells not only during acute T. cruzi infection but also in viral infections. For example, in human immunodeficiency virus or Epstein-Barr virus infections, the percentage of DP cells can increase to $20 \%$ of all circulating lymphocytes [95-97]. This fluctuation is also present in the secondary lymph nodes as we demonstrated in the experimental model of Chagas disease, in which DP-cell subset increases up to 16 times in subcutaneous lymph nodes $[83,85]$. During the course of infection, these peripheral DP cells acquire an activated phenotype similar to what is described for activated and memory single-positive T cells with high IFN- $\gamma$ production, $\mathrm{CD} 44^{+} \mathrm{CD} 9^{+}$expression, and cytotoxic activity [62].

Furthermore, similar to previous studies showing high cytotoxic activity and effector memory phenotype of extrathymic DP cells in cynomolgus monkeys and in a chimpanzee experimental infection with hepatitis $C$ virus [95], our results indicate that the DP cells purified from peripheral lymphoid tissues of chagasic animals show cytotoxic activity as compared to naïve single-positive $\mathrm{CD} 4^{+}$or $\mathrm{CD} 8^{+} \mathrm{T}$ cells.

Most likely, the presence of peripheral, mature, and activated DP lymphocytes challenges the perception of the T-cell populations involved in adaptive immune responses during the infection. The presence of peripheral activated DP cells with potentially autoreactive TCR may contribute to the immunopathological events possible related to several pathogen infections. In the Chagas disease model, we have demonstrated that increased percentages of peripheral blood subset of DP cells exhibiting an activated HLA-DR ${ }^{+}$phenotype are associated with severe cardiac forms of human chronic Chagas disease [62]. The role of these HLA-DR DP T cells in myocardial damage and host pathologies is unknown. However, correlations between the changes in the numbers of DP T-cell subsets and the extent of inflammatory lesions may represent a clinical marker of disease progression in parasitic infections and may help the design of novel therapeutic approaches for controlling infectious diseases.

\section{Abbreviations}

T. cruzi: Trypanosoma cruzi

DP T cells: $\mathrm{CD}^{+} \mathrm{CD}^{+}$double-positive T cells

AIRE: Autoimmune regulator gene

TRAs: Tissue-restricted antigens

TCR: $\quad$ T cell receptor

TEC: $\quad$ Thymic epithelial cells.

\section{Acknowledgments}

The work presented here has been partially funded with grants from CNPq, Capes, Faperj, and Fiocruz (Brazil).

\section{References}

[1] P. E. Love and A. Bhandoola, "Signal integration and crosstalk during thymocyte migration and emigration," Nature Reviews Immunology, vol. 11, no. 7, pp. 469-477, 2011.

[2] W. Savino and M. Dardenne, "Neuroendocrine control of thymus physiology," Endocrine Reviews, vol. 21, no. 4, pp. 412443, 2000.

[3] W. Savino, "Neuroendocrine control of T cell development in mammals: role of growth hormone in modulating thymocyte migration," Experimental Physiology, vol. 92, no. 5, pp. 813817, 2007.

[4] P. C. Fonseca, O. K. Nihei, M. Urban-Maldonado et al., "Characterization of connexin 30.3 and 43 in thymocytes," Immunology Letters, vol. 94, no. 1-2, pp. 65-75, 2004.

[5] W. Savino, D. A. Mendes-Da-Cruz, S. Smaniotto, E. SilvaMonteiro, and D. M. S. Villa-Verde, "Molecular mechanisms governing thymocyte migration: combined role of chemokines and extracellular matrix," Journal of Leukocyte Biology, vol. 75, no. 6, pp. 951-961, 2004.

[6] O. K. Nihei, A. C. C. de Carvalho, D. C. Spray, W. Savino, and L. A. Alves, "A novel form of cellular communication among thymic epithelial cells: intercellular calcium wave propagation," American Journal of Physiology-Cell Physiology, vol. 285, no. 5, pp. C1304-C1313, 2003.

[7] W. Savino, D. A. Mendes-da-Cruz, J. S. Silva, M. Dardenne, and V. Cotta-de-Almeida, "Intrathymic T-cell migration: a combinatorial interplay of extracellular matrix and chemokines?" Trends in Immunology, vol. 23, no. 6, pp. 305-313, 2002.

[8] J. S. P. Ocampo, J. M. de Brito, E. Corrêa-de-Santana, R. Borojevic, D. M. S. Villa-Verde, and W. Savino, "Laminin211 controls thymocyte-thymic epithelial cell interactions," Cellular Immunology, vol. 254, no. 1, pp. 1-9, 2008.

[9] W. Savino, "The thymus is a common target organ in infectious diseases," PLoS Pathogens, vol. 2, no. 6, p. e62, 2006.

[10] S. Ayres-Martins, J. Lannes-Vieira, D. A. Farias-De-Oliveira, J. M. Brito, D. M. S. Villa-Verde, and W. Savino, "Phagocytic cells of the thymic reticulum interact with thymocytes via extracellular matrix ligands and receptors," Cellular Immunology, vol. 229, no. 1, pp. 21-30, 2004. 
[11] E. Ladi, X. Yin, T. Chtanova, and E. A. Robey, "Thymic microenvironments for T cell differentiation and selection," Nature Immunology, vol. 7, no. 4, pp. 338-343, 2006.

[12] D. M. S. Villa-Verde, E. Silva-Monteiro, M. G. Jasiulionis et al., "Galectin-3 modulates carbohydrate-dependent thymocyte interactions with the thymic microenvironment," European Journal of Immunology, vol. 32, no. 5, pp. 1434-1444, 2002.

[13] W. Savino, S. R. Dalmau, and V. C. Dealmeida, "Role of extracellular matrix-mediated interactions in thymocyte migration," Developmental Immunology, vol. 7, no. 2-4, pp. 279291, 2000.

[14] M. L. Scimone, I. Aifantis, I. Apostolou, H. von Boehmer, and U. H. von Andrian, "A multistep adhesion cascade for lymphoid progenitor cell homing to the thymus," Proceedings of the National Academy of Sciences of the United States of America, vol. 103, no. 18, pp. 7006-7011, 2006.

[15] U. H. von Andrian and C. R. Mackay, "T-cell function and migration: two sides of the same coin," The New England Journal of Medicine, vol. 343, no. 14, pp. 1020-1034, 2000.

[16] E. V. Rothenberg, "T cell lineage commitment: identity and renunciation," Journal of Immunology, vol. 186, no. 12, pp. 6649-6655, 2011.

[17] P. C. Trampont, A. C. Tosello-Trampont, Y. Shen et al., "CXCR4 acts as a costimulator during thymic $\beta$-selection," Nature Immunology, vol. 11, no. 2, pp. 162-170, 2010.

[18] J. Zhang, Y. Gong, X. Shao et al., "Asynchronism of thymocyte development in vivo and in vitro," DNA and Cell Biology, vol. 26, no. 1, pp. 19-27, 2007.

[19] W. Savino, M. Dardenne, L. A. Velloso, and S. D. Silvabarbosa, "The thymus is a common target in malnutrition and infection," British Journal of Nutrition, vol. 98, supplement 1, pp. S11-S16, 2007.

[20] K. A. Hogquist, T. A. Baldwin, and S. C. Jameson, "Central tolerance: learning self-control in the thymus," Nature Reviews Immunology, vol. 5, no. 10, pp. 772-782, 2005.

[21] S. Sakaguchi, T. Yamaguchi, T. Nomura, and M. Ono, "Regulatory T cells and immune tolerance," Cell, vol. 133, no. 5, pp. 775-787, 2008.

[22] H. E. Lynch, G. L. Goldberg, A. Chidgey, M. R. M. van den Brink, R. Boyd, and G. D. Sempowski, "Thymic involution and immune reconstitution," Trends in Immunology, vol. 30, no. 7, pp. 366-373, 2009.

[23] W. H. Chen, B. F. Kozlovsky, R. B. Effros, B. Grubeck-Loebenstein, R. Edelman, and M. B. Sztein, "Vaccination in the elderly: an immunological perspective," Trends in Immunology, vol. 30, no. 7, pp. 351-359, 2009.

[24] M. E. Weksler, G. Pawelec, and C. Franceschi, "Immune therapy for age-related diseases," Trends in Immunology, vol. 30, no. 7, pp. 344-350, 2009.

[25] P. C. S. Souto, V. N. Brito, J. Gameiro, M. A. da Cruz-Höfling, and L. Verinaud, "Programmed cell death in thymus during experimental paracoccidioidomycosis," Medical Microbiology and Immunology, vol. 192, no. 4, pp. 225-229, 2003.

[26] I. Ljungstrom and G. Huldt, "Effect of experimental trichinosis on unrelated humoral and cell mediated immunity," Acta Pathologica et Microbiologica Scandinavica-cSection C, vol. 85, no. 2, pp. 131-141, 1977.

[27] C. Godfraind, K. V. Holmes, and J. P. Coutelier, "Thymus involution induced by mouse hepatitis virus A59 in BALB/c mice," Journal of Virology, vol. 69, no. 10, pp. 6541-6547, 1995.

[28] T. R. Gibb, M. Bray, T. W. Geisbert et al., "Pathogenesis of experimental Ebola Zaire virus infection in BALB/c mice," Journal of Comparative Pathology, vol. 125, no. 4, pp. 233-242, 2001.
[29] W. Savino, M. Dardenne, and C. Marche, "Thymic epithelium in AIDS. An immunohistologic study," American Journal of Pathology, vol. 122, no. 2, pp. 302-307, 1986.

[30] M. C. Leite-de-Moraes, M. Hontebeyrie-Joskowicz, M. Dardenne, and W. Savino, "Modulation of thymocyte subsets during acute and chronic phases of experimental Trypanosoma cruzi infection," Immunology, vol. 77, no. 1, pp. 95-98, 1992.

[31] W. Savino, M. C. de Moraes, S. D. Barbosa, E. C. da Fonseca, V. C. de Almeida, and M. Hontebeyrie-Joscowicz, "Is the thymus a target organ in infectious diseases?" Memorias do Instituto Oswaldo Cruz, vol. 87, supplement 5, pp. 73-78, 1992.

[32] M. C. L. de Moraes, M. Hontebeyrie-Joskowicz, F. Leboulenger, W. Savino, M. Dardenne, and F. Lepault, "Studies on the thymus in Chagas' disease. II. Thymocyte subset fluctuations in Trypanosoma cruzi-infected mice: relationship to stress," Scandinavian Journal of Immunology, vol. 33, no. 3, pp. 267$275,1991$.

[33] D. L. Sodora, J. M. Milush, F. Ware et al., "Decreased levels of recent thymic emigrants in peripheral blood of simian immunodeficiency virus-infected macaques correlate with alterations within the thymus," Journal of Virology, vol. 76, no. 19, pp. 9981-9990, 2002.

[34] H. Suzuki, M. Motohara, A. Miyake et al., "Intrathymic effect of acute pathogenic SHIV infection on T-lineage cells in newborn macaques," Microbiology and Immunology, vol. 49, no. 7, pp. 667-679, 2005.

[35] P. Price, S. D. Olver, M. Silich, T. Z. Nador, S. Yerkovich, and S. G. Wilson, "Adrenalitis and the adrenocortical response of resistant and susceptible mice to acute murine cytomegalovirus infection," European Journal of Clinical Investigation, vol. 26, no. 9, pp. 811-819, 1996.

[36] S. R. Watson, T. J. Redington, T. B. Miller, and W. E. Bullock, "Flow microfluorometry analysis of alterations in T-lymphocyte subsets during murine listeriosis," Infection and Immunity, vol. 45, no. 2, pp. 372-377, 1984.

[37] E. Seixas and D. Ostler, "Plasmodium chabaudi chabaudi (AS): differential cellular responses to infection in resistant and susceptible mice," Experimental Parasitology, vol. 110, no. 4, pp. 394-405, 2005.

[38] S. R. Wellhausen and D. L. Boros, "Atrophy of the thymic cortex in mice with granulomatous Schistosomiasis mansoni," Infection and Immunity, vol. 35, no. 3, pp. 1063-1069, 1982.

[39] S. R. Watson, T. B. Miller, T. J. Redington, and W. E. Bullock, "Immunoregulation in experimental disseminated histoplasmosis: flow microfluorometry (FMF) of the Thy and Lyt phenotypes of T lymphocytes from infected mice," Journal of Immunology, vol. 131, no. 2, pp. 984-990, 1983.

[40] J. A. Molinari, R. H. Cypess, and B. N. Appel, "Effect of infection with Trichinella spiralis and BCG on thymic histology," International Archives of Allergy and Applied Immunology, vol. 48, no. 6, pp. 776-783, 1975.

[41] C. F. Andrade, J. Gameiro, P. R. A. Nagib et al., "Thymic alterations in Plasmodium berghei-infected mice," Cellular Immunology, vol. 253, no. 1-2, pp. 1-4, 2008.

[42] C. Francelin, L. C. Paulino, J. Gameiro, and L. Verinaud, "Effects of Plasmodium berghei on thymus: high levels of apoptosis and premature egress of CD4(+)CD8 $(+)$ thymocytes in experimentally infected mice," Immunobiology, vol. 216, no. 10, pp. 1148-1154, 2011.

[43] W. Savino, M. C. Leite-de-Moraes, M. Hontebeyrie-Joskowicz, and M. Dardenne, "Studies on the thymus in Chagas' disease. I. Changes in the thymic microenvironment in mice acutely infected with Trypanosoma cruzi," European Journal of Immunology, vol. 19, no. 9, pp. 1727-1733, 1989. 
[44] A. R. Pérez, E. Roggero, A. Nicora et al., "Thymus atrophy during Trypanosoma cruzi infection is caused by an immunoendocrine imbalance," Brain, Behavior, and Immunity, vol. 21, no. 7, pp. 890-900, 2007.

[45] C. E. Tanner, H. C. Lim, and G. Faubert, "Trichinella spiralis: changes caused in the mouse's thymic, splenic, and lymph node cell populations," Experimental Parasitology, vol. 45, no. 1, pp. 116-127, 1978.

[46] J. M. Mansfield and O. Bagasra, "Lymphocyte function in experimental African trypanosomiasis. I.B. cell responses to helper T cell-independent and-dependent antigens," Journal of Immunology, vol. 120, no. 3, pp. 759-765, 1978.

[47] P. K. Murray, F. W. Jennings, M. Murray, and G. M. Urquhart, "The nature of immunosuppression of Trypanosoma brucei infections in mice. II. The role of the T and B lymphocytes," Immunology, vol. 27, no. 5, pp. 825-840, 1974.

[48] R. P. Artz and W. E. Bullock, "Immunoregulatory responses in experimental disseminated histoplasmosis: lymphoid organ histopathology and serological studies," Infection and Immunity, vol. 23, no. 3, pp. 884-892, 1979.

[49] J. K. Beverley and L. Henry, "Histopathological changes caused by congenital toxoplasmosis in mice," Lyon Médical, vol. 225, no. 9, pp. 883-887, 1971.

[50] M. D. C. L. de Moraes, P. Minoprio, M. Dy, M. Dardenne, W. Savino, and M. Hontebeyrie-Joskowicz, "Endogenous IL10 and IFN- $\gamma$ production controls thymic cell proliferation in mice acutely infected by Trypanosoma cruzi," Scandinavian Journal of Immunology, vol. 39, no. 1, pp. 51-58, 1994.

[51] A. R. Pérez, O. Bottasso, and W. Savino, "The impact of infectious diseases upon neuroendocrine circuits," NeuroImmunoModulation, vol. 16, no. 2, pp. 96-105, 2009.

[52] Z. Kronfol and D. G. Remick, "Cytokines and the brain: implications for clinical psychiatry," American Journal of Psychiatry, vol. 157, no. 5, pp. 683-694, 2000.

[53] A. del Rey, I. Klusman, and H. O. Besedovsky, "Cytokines mediate protective stimulation of glucocorticoid output during autoimmunity: involvement of IL-1," American Journal of Physiology, vol. 275, no. 4, part 2, pp. R1146-R1151, 1998.

[54] H. Besedovsky, A. del Rey, E. Sorkin, and C. A. Dinarello, "Immunoregulatory feedback between interleukin-1 and glucocorticoid hormones," Science, vol. 233, no. 4764, pp. 652654, 1986.

[55] A. V. Turnbull and C. L. Rivier, "Regulation of the hypothalamic-pituitary-adrenal axis by cytokines: actions and mechanisms of action," Physiological Reviews, vol. 79, no. 1, pp. 1-71, 1999.

[56] E. Corrêa-de-Santana, M. Paez-Pereda, M. Theodoropoulou et al., "Hypothalamus-pituitary-adrenal axis during Trypanosoma cruzi acute infection in mice," Journal of Neuroimmunology, vol. 173, no. 1-2, pp. 12-22, 2006.

[57] E. Corrêa-de-Santana, F. Pinto-Mariz, and W. Savino, "Immunoneuroendocrine interactions in Chagas disease," Annals of the New York Academy of Sciences, vol. 1088, pp. 274-283, 2006.

[58] J. F. A. P. Miller, "The golden anniversary of the thymus," Nature Reviews Immunology, vol. 11, no. 7, pp. 489-495, 2011.

[59] L. Klein, M. Hinterberger, G. Wirnsberger, and B. Kyewski, "Antigen presentation in the thymus for positive selection and central tolerance induction," Nature Reviews Immunology, vol. 9, no. 12, pp. 833-844, 2009.

[60] J. Derbinski, A. Schulte, B. Kyewski, and L. Klein, "Promiscuous gene expression in medullary thymic epithelial cells mirrors the peripheral self," Nature Immunology, vol. 2, no. 11, pp. 1032-1039, 2001.
[61] M. S. Anderson, E. S. Venanzi, L. Klein et al., "Projection of an immunological self shadow within the thymus by the aire protein," Science, vol. 298, no. 5597, pp. 1395-1401, 2002.

[62] A. Morrot, E. Terra-Granado, A. R. Pérez et al., "Chagasic thymic atrophy does not affect negative selection but results in the export of activated $\mathrm{CD} 4^{+} \mathrm{CD}^{+} \mathrm{T}$ cells in severe forms of human disease," PLoS Neglected Tropical Diseases, vol. 5, no. 8, Article ID e1268, 2011.

[63] J. de Meis, A. Morrot, D. A. Farias-de-Oliveira, D. M. S. VillaVerde, and W. Savino, "Differential regional immune response in Chagas disease," PLoS Neglected Tropical Diseases, vol. 3, no. 7, p. e417, 2009.

[64] E. Silva-Monteiro, L. R. Lorenzato, O. K. Nihei et al., "Altered expression of galectin-3 induces cortical thymocyte depletion and premature exit of immature thymocytes during Trypanosoma cruzi infection," American Journal of Pathology, vol. 170, no. 2, pp. 546-556, 2007.

[65] E. Roggero, A. R. Pérez, O. A. Bottasso, H. O. Besedovsky, and A. del Rey, "Neuroendocrine-immunology of experimental Chagas' disease," Annals of the New York Academy of Sciences, vol. 1153, pp. 264-271, 2009.

[66] D. Wang, N. Müller, K. G. McPherson, and H. M. Reichardt, "Glucocorticoids engage different signal transduction pathways to induce apoptosis in thymocytes and mature T cells," Journal of Immunology, vol. 176, no. 3, pp. 1695-1702, 2006.

[67] R. M. F. Libonati, B. B. de Mendonça, J. A. Maués, J. A. S. Quaresma, and J. M. de Souza, "Some aspects of the behavior of the hypothalamus-pituitary-adrenal axis in patients with uncomplicated Plasmodium falciparum malaria: cortisol and dehydroepiandrosterone levels," Acta Tropica, vol. 98, no. 3, pp. 270-276, 2006.

[68] M. Reincke, C. Heppner, F. Petzke et al., "Impairment of adrenocortical function associated with increased plasma tumor necrosis factor-alpha and interleukin-6 concentrations in African trypanosomiasis," Neuroimmunomodulation, vol. 1, no. 1, pp. 14-22, 1994.

[69] E. Roggero, A. R. Pérez, M. Tamae-Kakazu et al., "Edogenous glucocorticoids cause thymus atrophy but are protective during acute Trypanosoma cruzi infection," Journal of Endocrinology, vol. 190, no. 2, pp. 495-503, 2006.

[70] C. A. W. Evans, M. S. Harbuz, T. Ostenfeld, A. Norrish, and J. M. Blackwell, "Nramp1 is expressed in neurons and is associated with behavioural and immune responses to stress," Neurogenetics, vol. 3, no. 2, pp. 69-78, 2001.

[71] M. R. Ruiz, A. G. Quiñones, N. L. Díaz, and F. J. Tapia, "Acute immobilization stress induces clinical and neuroimmunological alterations in experimental murine cutaneous leishmaniasis," British Journal of Dermatology, vol. 149, no. 4, pp. 731-738, 2003.

[72] J. Morales-Montor, E. Newhouse, F. Mohamed, A. Baghdadi, and R. T. Damian, "Altered levels of hypothalamic-pituitaryadrenocortical axis hormones in baboons and mice during the course of infection with Schistosoma mansoni," Journal of Infectious Diseases, vol. 183, no. 2, pp. 313-320, 2001.

[73] A. R. Pérez, M. Tamae-Kakazu, M. F. Pascutti et al., "Deficient control of Trypanosoma cruzi infection in C57BL/6 mice is related to a delayed specific IgG response and increased macrophage production of pro-inflammatory cytokines," Life Sciences, vol. 77, no. 16, pp. 1945-1959, 2005.

[74] M. Mantuano-Barradas, A. Henriques-Pons, T. C. AraújoJorge, F. di Virgilio, R. Coutinho-Silva, and P. M. Persechini, "Extracellular ATP induces cell death in $\mathrm{CD} 4^{+} / \mathrm{CD}^{+}$doublepositive thymocytes in mice infected with Trypanosoma cruzi," Microbes and Infection, vol. 5, no. 15, pp. 1363-1371, 2003. 
[75] J. Mucci, A. Hidalgo, E. Mocetti, P. F. Argibay, M. S. Leguizamón, and O. Campetella, "Thymocyte depletion in Trypanosoma cruzi infection is mediated by trans-sialidase-induced apoptosis on nurse cells complex," Proceedings of the National Academy of Sciences of the United States of America, vol. 99, no. 6, pp. 3896-3901, 2002.

[76] M. S. Leguizamón, E. Mocetti, H. G. Rivello, P. Argibay, and O. Campetella, "Trans-sialidase from Trypanosoma cruzi induces apoptosis in cells from the immune system in vivo," Journal of Infectious Diseases, vol. 180, no. 4, pp. 1398-1402, 1999.

[77] J. Mucci, E. Mocetti, M. S. Leguizamón, and O. Campetella, "A sexual dimorphism in intrathymic sialylation survey is revealed by the trans-sialidase from Trypanosoma cruzi," Journal of Immunology, vol. 174, no. 8, pp. 4545-4550, 2005.

[78] A. Henriques-Pons, J. DeMeis, V. Cotta-De-Almeida, W. Savino, and T. C. Araújo-Jorge, "Fas and perforin are not required for thymus atrophy induced by Trypanosoma cruzi infection," Experimental Parasitology, vol. 107, no. 1-2, pp. 14, 2004.

[79] W. Savino, D. M. S. Villa-Verde, D. A. Mendes-da-Cruz et al., "Cytokines and cell adhesion receptors in the regulation of immunity to Trypanosoma cruzi," Cytokine and Growth Factor Reviews, vol. 18, no. 1-2, pp. 107-124, 2007.

[80] R. Chammas, M. G. Jasiulionis, F. Jin, D. M. Villa-Verde, and V. N. Reinhold, "Carbohydrate-binding proteins in cell-matrix interactions," Brazilian Journal of Medical and Biological Research, vol. 27, no. 9, pp. 2169-2179, 1994.

[81] J. Lannes-Vieira, R. Chammas, D. M. S. Villa-Verde et al., "Extracellular matrix components of the mouse thymic microenvironment: III—-thymic epithelial cells express the VLA6 complex that is involved in laminin-mediated interactions with thymocytes," International Immunology, vol. 5, no. 11, pp. 1421-1430, 1993.

[82] W. Savino, D. M. S. Villa-Verde, and J. Lannes-Vieira, "Extracellular matrix proteins in intrathymic T-cell migration and differentiation?" Immunology Today, vol. 14, no. 4, pp. 158161, 1993.

[83] V. Cotta-de-Almeida, A. Bonomo, D. A. Mendes-da-Cruz et al., "Trypanosoma cruzi infection modulates intrathymic contents of extracellular matrix ligands and receptors and alters thymocyte migration," European Journal of Immunology, vol. 33, no. 9, pp. 2439-2448, 2003.

[84] D. A. Mendes-da-Cruz, J. S. Silva, V. Cotta-de-Almeida, and W. Savino, "Altered thymocyte migration during experimental acute Trypanosoma cruzi infection: combined role of fibronectin and the chemokines CXCL12 and CCL4," European Journal of Immunology, vol. 36, no. 6, pp. 1486-1493, 2006.

[85] D. A. Mendes-da-Cruz, J. de Meis, V. Cotta-de-Almeida, and W. Savino, "Experimental Trypanosoma cruzi infection alters the shaping of the central and peripheral T-cell repertoire," Microbes and Infection, vol. 5, no. 10, pp. 825-832, 2003.

[86] V. Cotta-de-Almeida, A. L. Bertho, D. M. S. Villa-Verde, and W. Savino, "Phenotypic and functional alterations of thymic nurse cells following acute Trypanosoma cruzi infection," Clinical Immunology and Immunopathology, vol. 82, no. 2, pp. 125-132, 1997.

[87] J. Gameiro, P. R. A. Nagib, C. F. Andrade et al., "Changes in cell migration-related molecules expressed by thymic microenvironment during experimental Plasmodium berghei infection: consequences on thymocyte development," Immunology, vol. 129, no. 2, pp. 248-256, 2010.

[88] J. de Meis, L. M. S. Ferreira, L. V. C. Guillermo, E. M. Silva, G. A. DosReis, and M. D. F. Lopes, "Apoptosis differentially regulates mesenteric and subcutaneous lymph node immune responses to Trypanosoma cruzi," European Journal of Immunology, vol. 38, no. 1, pp. 139-146, 2008.

[89] N. Chamond, A. Cosson, N. Coatnoan, and P. Minoprio, "Proline racemases are conserved mitogens: characterization of a Trypanosoma vivax proline racemase," Molecular and Biochemical Parasitology, vol. 165, no. 2, pp. 170-179, 2009.

[90] P. M. Minoprio, A. Coutinho, M. Joskowicz, M. R. D. Lima, and H. Eisen, "Polyclonal lymphocyte responses to murine Trypanosoma cruzi infection. II. Cytotoxic T lymphocytes," Scandinavian Journal of Immunology, vol. 24, no. 6, pp. 669679, 1986.

[91] P. M. Minoprio, H. Eisen, L. Forni, M. R. D. Lima, M. Joskowicz, and A. Coutinho, "Polyclonal lymphocyte responses to murine Trypanosoma cruzi infection. I. Quantitation of both T- and B-cell responses," Scandinavian Journal of Immunology, vol. 24, no. 6, pp. 661-668, 1986.

[92] J. de Meis, D. A. Mendes-da-Cruz, D. A. Farias-de-Oliveira et al., "Atrophy of mesenteric lymph nodes in experimental Chagas' disease: differential role of Fas/Fas-L and TNFRI/TNF pathways," Microbes and Infection, vol. 8, no. 1, pp. 221-231, 2006.

[93] F. Cardillo, A. Nomizo, and J. Mengel, "The role of the thymus in modulating $\gamma \delta$ T cell suppressor activity during experimental Trypanosoma cruzi infections," International Immunology, vol. 10, no. 2, pp. 107-116, 1998.

[94] O. A. Bottasso, S. S. Revelli, H. Davila et al., "Enhanced myocardial lesions in chronically Trypanosoma cruzi-infected rats subjected to adult thymectomy," Immunology Letters, vol. 37, no. 2-3, pp. 175-180, 1993.

[95] E. A. Fritz, J. B. Geisbert, T. W. Geisbert, L. E. Hensley, and D. S. Reed, "Cellular immune response to Marburg virus infection in cynomolgus macaques," Viral Immunology, vol. 21, no. 3, pp. 355-363, 2008.

[96] G. J. Hughes, A. Cochrane, C. Leen, S. Morris, J. E. Bell, and P. Simmonds, "HIV-1-infected $\mathrm{CD} 8^{+} \mathrm{CD}^{+} \mathrm{T}$ cells decay in vivo at a similar rate to infected CD4 T cells during HAART," AIDS, vol. 22, no. 1, pp. 57-65, 2008.

[97] M. Nascimbeni, S. Pol, and B. Saunier, "Distinct CD $4^{+} \mathrm{CD} 8^{+}$ double-positive T cells in the blood and liver of patients during chronic hepatitis B and C," PLoS ONE, vol. 6, no. 5, Article ID e20145, 2011. 

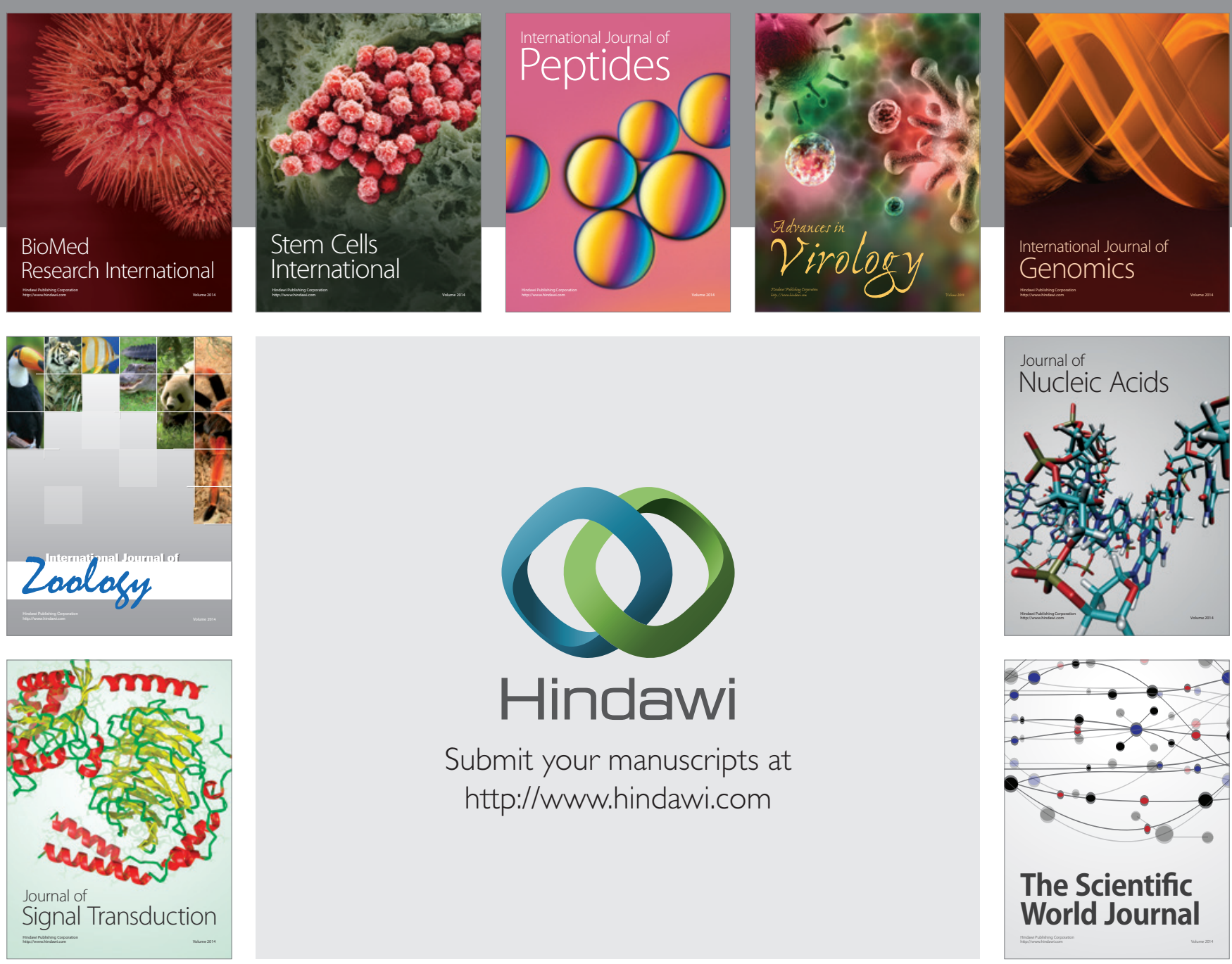

Submit your manuscripts at

http://www.hindawi.com
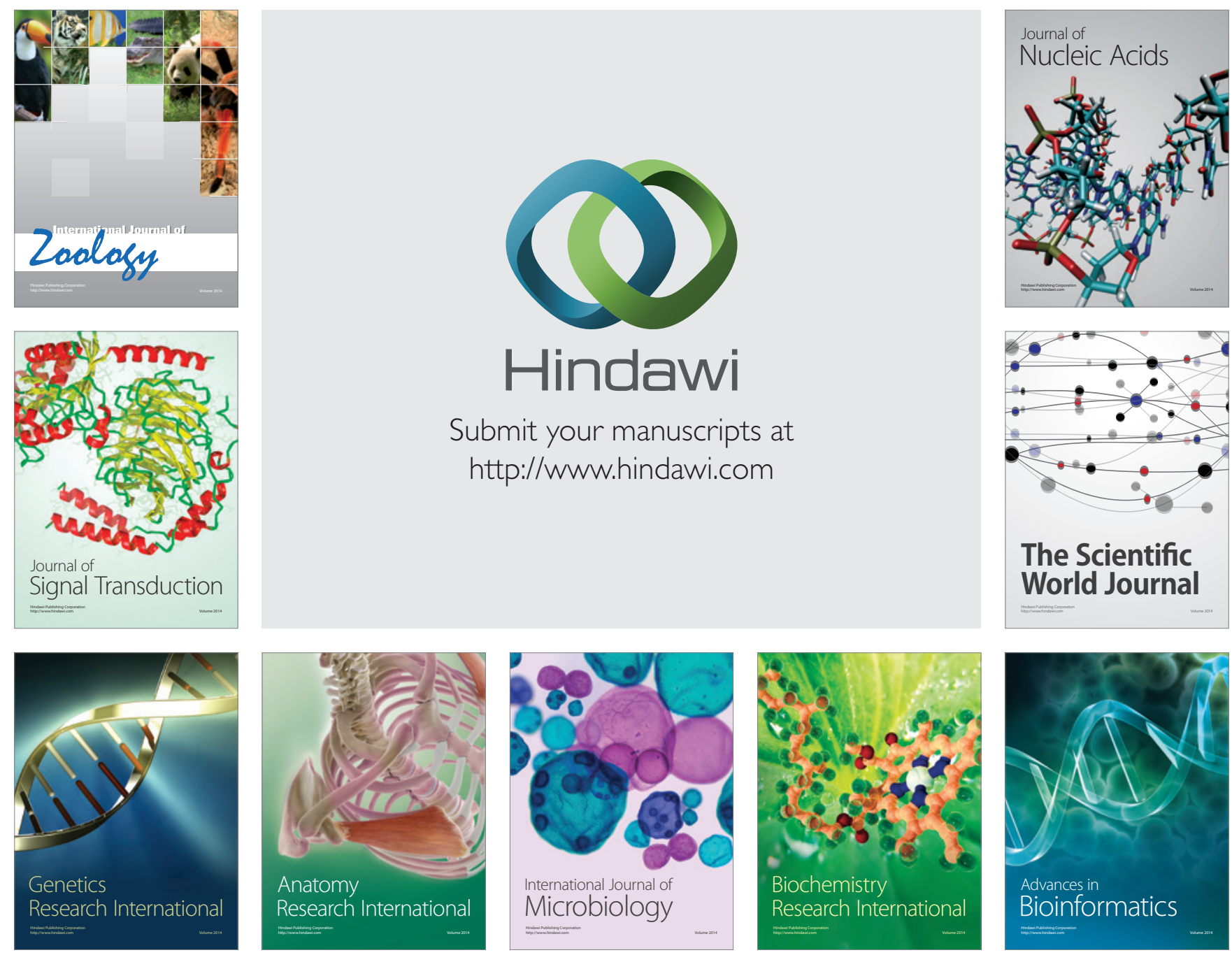

The Scientific World Journal
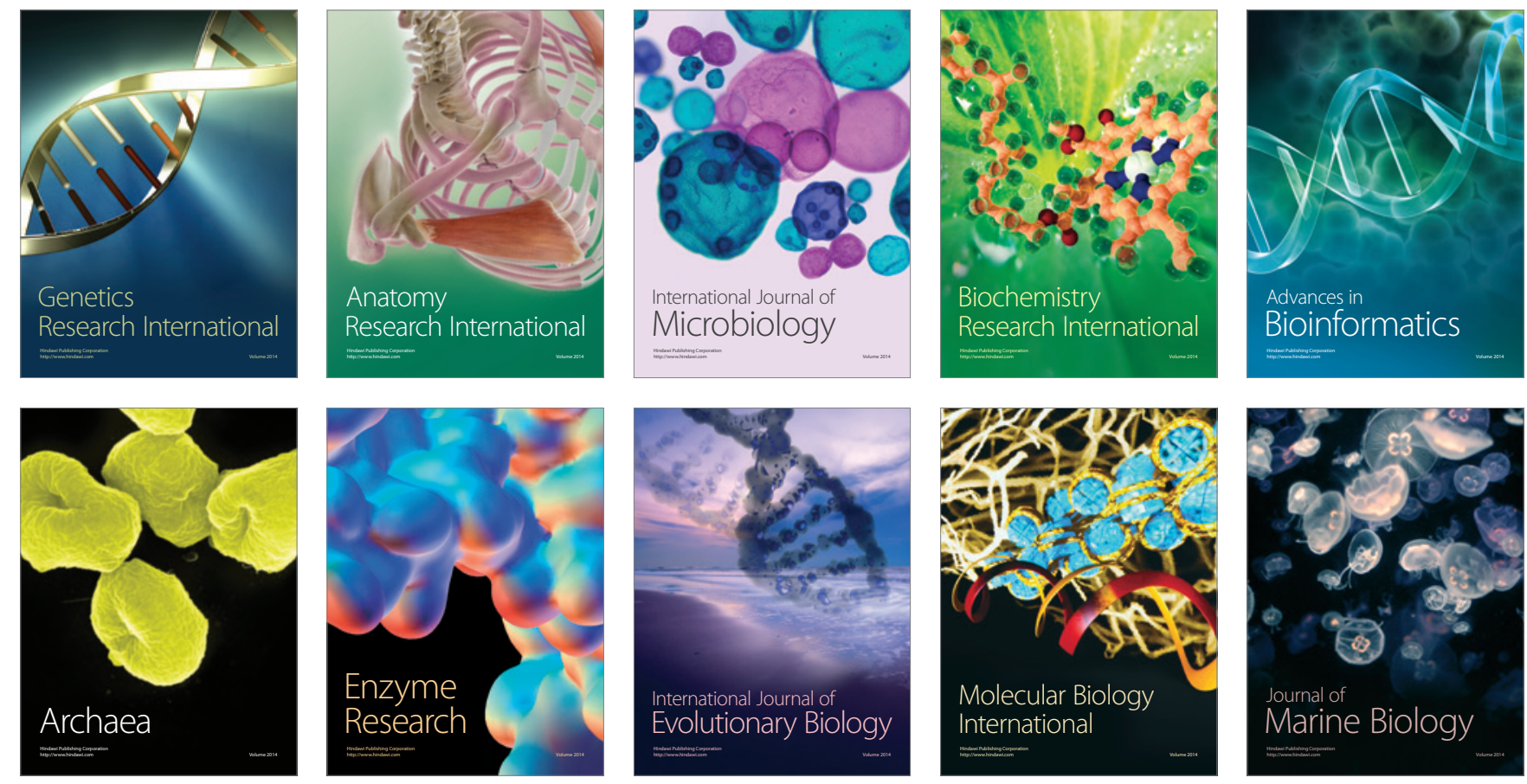